\title{
PHASE CONTROL IN A TWO-ELEMENT FOLDED WAVEGUIDE ARRAY*
}

\author{
Glenn R. Haste \\ Oak Ridge National Laboratory, Oak Ridge, TN 37831-8071, USA
}

\begin{abstract}
A pair of folded waveguides have been used to determine the mutual coupling and to measure the field distributions for the magnetic field components for single units and for a pair. The phase difference controls the field distribution and the Fourier spectrum.

\section{INTRODUCTION}

The folded waveguide ${ }^{1}$ FWG is an if launching structure, particularly suitable for launching ion cyclotron range of frequency (ICRF) waves in the frequency range of about $80-500 \mathrm{MHz}$. A single $78-\mathrm{MHz}$ FWG has been operated at $740 \mathrm{~kW}$ with plasma, ${ }^{2}$ so the high-power performance of the FWG is well demonstrated.This paper addresses FWG performance as an element in an array of launchers. Specifically, adjacent FWGs are found to have very weak coupling. This weak coupling permits considerable control of the phase and amplitude of the fields produced by acj.jacent FWGs. The measurements described here have been with either one or a pair of models, one-fifth the size of the $78-\mathrm{MHz}$ unit, operating at five times its frequency. Loop probes have been used to map out the field distributions, using an automated loop positioning system developed by F. W. Baity. Field polarizations corresponding to radial, poloidal, and toroidal field components have been measured. For the poloidal and toroidal components, a pair of measurements were made, with the probe orientation reversed between the two. The "true" signals are defined as those whose phase shifts by $180^{\circ}$ when the probe is turned through $180^{\circ}$, and the "spurious" signals are the residual signals. The maximum value of the true signal is defined to be real and positive. The phase difference at other points determines the real and imaginary parts.
\end{abstract}

\section{COUPLING}

Two identical FWGs were used. The resonant frequency ( $\left.f_{\text {res }}\right)$ of each was adjusted using a bolt through the back plate so that each FWG had precisely the same resonant frequency when isolated. The $f_{\text {res }}$ of a pair of adjacent FWGs was determined for several values of the phase difference between the drive power for the two. When the phase difference was zero, the $f_{\text {res }}$ was virtually unchanged from that for a single FWG. The $f_{\text {res }}$ increased with increasing phase difference, of either sign. The fractional change in $f_{\text {res }}$ reached a maximum of about $10^{-3}$ for a phase difference of $180^{\circ}$ This fractional change is taken to be equal to the mutual coupling between the two.

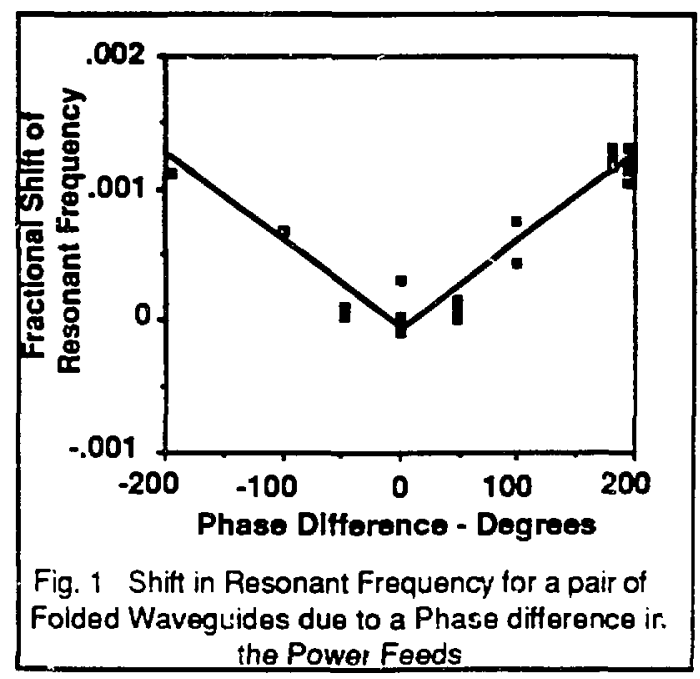

\footnotetext{
*Research sponsored by the Office of Fusion Energy, U.S. Deparment of Energy, under contract DE-
} AC05-84OR21400 with Martin Mariena Energy Systems, Inc.

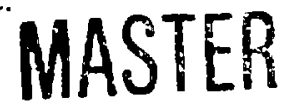




\section{FIELD DISTRIBUTION FOR A SINGLE FWG}

The spatial distributions of the various field components were measured when only one of the FWGs was excited. These field distributions, shown in Fig. 2, are very much like those for a loop antenna; the toroidal field component is a maximum at the center, falls to zerc at the top and bottom, and becomes negative beyond the sides of the FWG. The radial fieid has its maximum positive value on one side, at the center, and its maximum negative value on the other side, at the center. The radial field values go to zero at the top and bottom. The poloidal field vanishes along the horizontal and vertical midlines, reversing sign across each of those lines. The maximum (positive or negative) values occur near the top and bottom at the sides. These field distributions can be compared with those calculated by C'arter. ${ }^{3}$

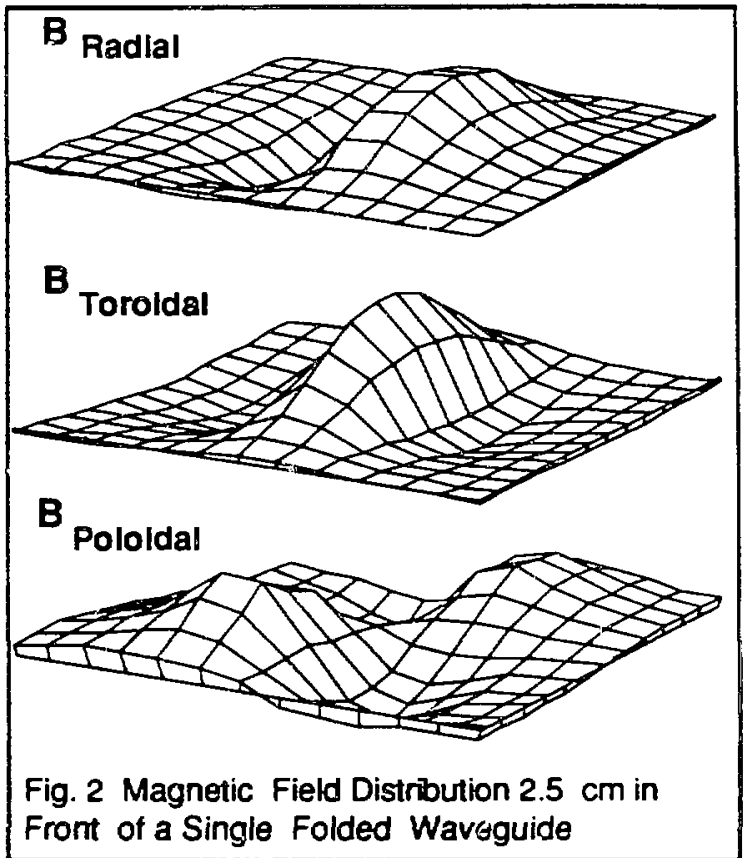

Since the coupling between two adjacent FWGs is so low, the field produced by each is determined solely by its driver power and is only weakly affected by the other FWG. The resultant field, for the two FWGs, is then simply the vector sum of the fields due to the two single FWGs.

\section{FIELD DISTRIBUTION FOR A PAIR OF FWGs}

Most of the measuremen:s for a pair of FWGs have been for the toroidal component. The real and imaginary field distributions of the toroidal component are shown in Fig. 3. These were measured $5 \mathrm{~cm}$ from the face of the FWG pairs and along

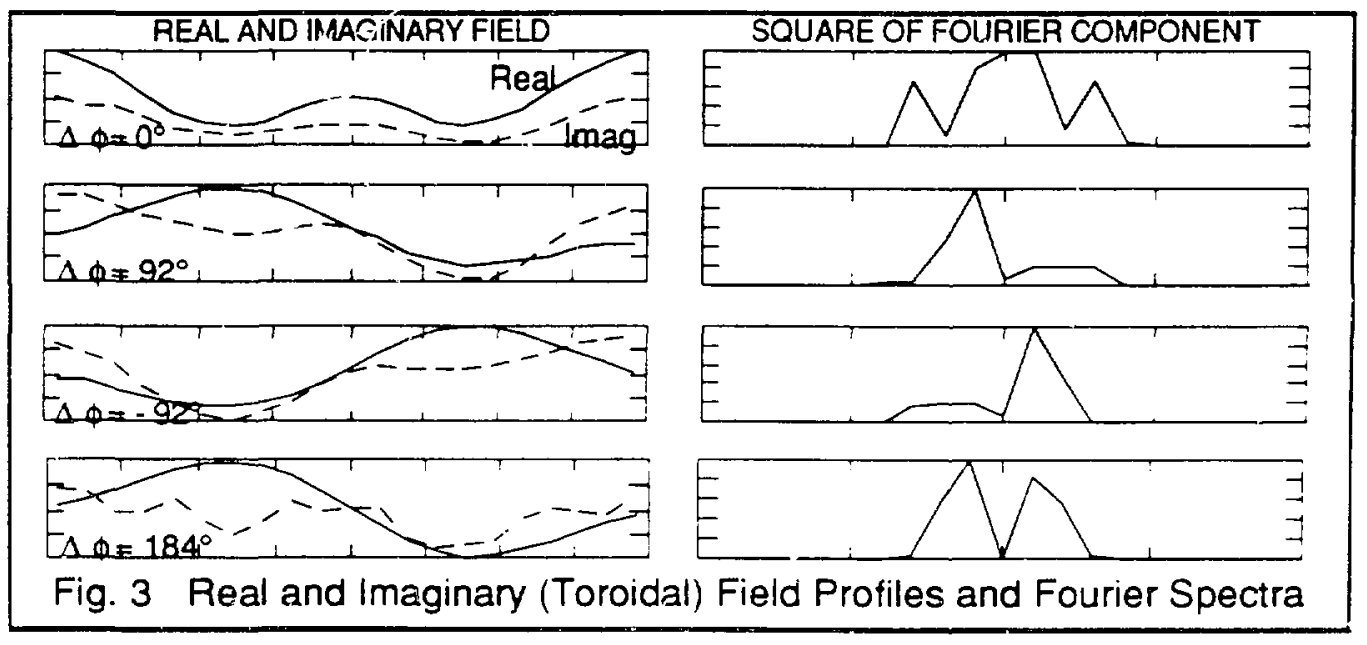


the center line. For $0^{\prime}$ and $184^{\circ}$ phase difference the field is predominantly real. At $\pm 92^{\circ}$ the imaginary part is nearly equal to the real part and is a maximum where the real part is zero. The Fourier spectrum is also shown. For $0^{\circ}$ or $184^{\circ}$ the spectrum is symmetric, and for $\pm 92^{\circ}$ it is asymmetric, with the asymmetry reversing when the sign is reversed.

Similar measurements were made for the poloidal component, also $5 \mathrm{~cm}$ from the FWG face. The field distribution (shown in Fig. 4) along a line near the top or bottom of the FWG pair (near the maximum of the fields) shows behavior similar to that of the toroidal component.

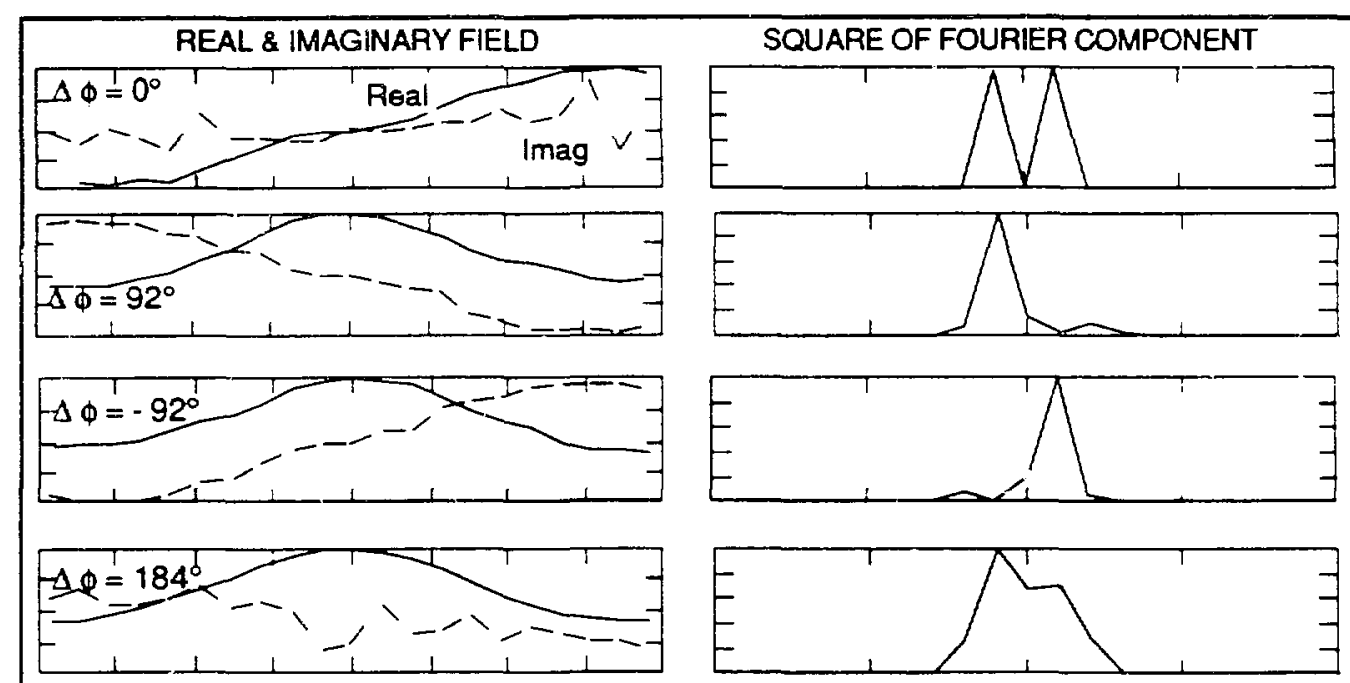

Fig. 4 Real and Imaginary (Poloidal) Field Profiles and Fourier Spectra

Toroidal field distributions were measured $1 \mathrm{~cm}$ from the face for phase differences between $40^{\circ}$ and $110^{\circ}$. The imaginary field was a maximum for a phase difference of $90^{\circ}$, and the Fourier spectra were asymmetric for all values of the phase difference. This behavior is consistent with that desioribed above.

Toroidal field distributions were also measured $2.5 \mathrm{~cm}$ from the face, for phase differences from $0^{\circ}$ to $90^{\circ}$. In this case, the ratio of imaginary to real fields did not vary as expected and as described above, nor did the Fourier spectra show the same asymmetry. It is unclear why this case differs from the others.

\section{SUMMARY}

The coupling between a pair of adjacent FWGs is observed to be $10^{-3}$ or less. The field distributions for the three components of the of magnetic field are about the same as those for a loop antenna. Composite field distributions for a pair of FWGs have also been measured and show that the small value of the mutual coupling permits considerable control over the resultant distributions and of their Fourier spectra, in particular, by varying the phase difference between the two FWGs. For $0^{\circ}$ or $180^{\circ}$ 
phase differences, the fields are primarily real. For other phase differences there are imaginary compcnents, whose magnitude reaches a maximum for $90^{\circ}$. In most cases, the Fourier spectrum is asymmetric for $90^{\circ}$, and the asymmetry reverses for $-90^{\circ}$ phase difference.

These features make arrays of FWGs attractive for launching ICRF power in the frequency range above about $80 \mathrm{MHz}$. Spectral control, for either heating or current drive, should be readily possible.

${ }^{1}$ T. L. Owens, IEEE Trans. Plasma Sci. PS-14 (6), 934 (1986).

${ }^{2}$ F. W. Baity, T. S. Bigelow M. D. Carter, W. L. Gardner, R. H. Goulding, G. R. Haste, D. J. Hoffman, D. O. Sparks, this conference.

${ }^{3}$ M. D. Carter, F. W. Baity, D. B. Batchelor, D. J. Hoffman, E. F. Jaeger, and

D. W. Swain, this conference.

\section{DISCLAIMER}

Thris report was prepared as an account of turk sponsored by an agency of the United States Government. Neither the United States Government nor any agency thereof, nor any of their employees, makes any warranty, express or implied, or assumes any legal liability or responsibility for the accuracy, completeness, or usefulness of any information. apparatus, product, or process disclosed, or represents that its use would not infringe prwately owned rights. Reference herein to any specific commercial product. process, of service by trade liame, trademark, manufacturer, or otherwise does nut necessarly constilute or imply its endorsement, recominendation, or favoring by the United States Government or any agency thereof The views and opimons of authors expressed herein do nol necessarily state or reflect those of the United States Government or any agency thereof 